\title{
Association of illicit drug use in adolescence with socioeconomic and criminal justice outcomes in adulthood: prospective findings from a UK national birth cohort
}

\author{
James White $\mathbb{C}^{1},{ }^{1}$ Steven Bell, ${ }^{2} \mathrm{G}$ David Batty $\mathbb{1}^{3}{ }^{3}$
}

\begin{abstract}
- Additional material is published online only. To view please visit the journal online (http://dx.doi.org/10.1136/ jech-2019-213282).

${ }^{1}$ Centre for Trials Research, Cardiff University, Cardiff, UK ${ }^{2}$ Cardiovascular Epidemiology Unit, Department of Public Health and Primary Care, The National Institute for Health Research Blood and Transplant Unit in Donor Health and Genomics, University of Cambridge, Cambridge, UK ${ }^{3}$ Epidemiology and Public Health, University College London, London, UK
\end{abstract}

Correspondence to Dr James White, Centre for Trials Research, Cardiff University, Cardiff CF14 4YS, UK; whitej11@cf.ac.uk

Received 23 September 2019 Revised 3 April 2020 Accepted 14 April 2020
Check for updates

(c) Author(s) (or their employer(s)) 2020. No commercial re-use. See rights and permissions. Published by BMJ.

To cite: White J, Bell S, Batty GD. J Epidemiol Community Health 2020;74:705-709.

\begin{abstract}
Background Illicit drug use in adolescence has been linked to drug use and poor mental health in adult life, but few studies have examined the relation between adult economic and criminal justice outcomes.

Methods We analysed data from 14082 participants (6999 women) in the 1970 British Birth Cohort Study. Illicit drug use over study members' lifetime and in the past year were self-reported at 16 years of age. Thirteen outcomes were self-reported at 30 years of age, including illicit drug use, smoking, problems with alcohol, mental and physical health, experience of socioeconomic disadvantage and experiences with the criminal justice system.

Results At 16 years of age, $20.3 \%$ of the participants had ever tried an illicit drug and $7.2 \%$ had used in the past year. After adjustment for childhood socioeconomic status and mental health problems, and following correction for multiple testing, there was a dose-response association between illicit drug use at 16 years with illicit drug use in adult life in the past year $(O R ; 95 \% \mathrm{Cl}-1.83$, 1.51 to 3.12$)$, experiencing homelessness $(1.74,1.16$ to $2.62)$, being arrested $(1.57,1.29$ to 1.92$)$ and cautioned $(1.97,1.50$ to 2.57$)$ by the police, and being found guilty at court $(1.73,1.34$ to 2.23$)$.
\end{abstract}

Conclusions Adolescent drug use was associated with an array of social and criminal outcomes in later life.

\section{INTRODUCTION}

Illicit drugs use in adolescence has been well examined in the context of later drug use $\mathrm{e}^{12}$ and mental health. ${ }^{3-5}$ Studies of twins discordant for cannabis use (ie, one used cannabis and the other did not) suggest a casual relation with later other illicit drugs, ${ }^{67}$ and systematic reviews report that regular cannabis use is associated with incident anxiety and mood disorders ${ }^{24}$ and psychosis. ${ }^{89}$ Less well understood is the impact of adolescent drug use on socioeconomic adversity and criminal justice outcomes. In the few studies conducted, early-onset cannabis use has been linked to poor educational achievement, ${ }^{10}{ }^{11}$ delinquency and violence. ${ }^{12}$ In the Victoria Adolescent Health Cohort Study, amphetamine use by 18 years of age was associated with increased risks for leaving with no qualifications, but not with unemployment, or receiving government benefits at 24 years. ${ }^{5}$ The potential confounding effect of early socioeconomic adversity was not accounted for in these analyses, and the role of psychological problems has also rarely been considered. Accordingly, we examined whether illicit drug use at 16 years of age is associated with an increased risk of an array of outcomes at 30 years, including poor health, socioeconomic disadvantage and experiences with the criminal justice system.

\section{METHODS}

We used data from the 1970 British Birth Cohort Study, an ongoing longitudinal study of children born in Great Britain between the Aril 5 and 11, 1970. A total of 16571 babies born in England, Scotland and Wales were enrolled at birth and have been followed up on eight occasions across the life course. For the purposes of the present analyses, we used data from enquiries about illicit drug taking at 16 years of age, and the first occasion these were collected. ${ }^{13}$ Study follow-up was at age 30 years. Parents of study participants gave written informed consent. This manuscript adheres to the guidelines for STrengthening the Reporting of OBservational studies in Epidemiology (STROBE). ${ }^{14}$

\section{Study participants}

At the age of 16 (1986), a national teachers strike and school examinations reduced study member participation. ${ }^{15}$ Of the 15999 members traced and invited to participate, information was obtained from 11615 (72.6\%). At the age of 30 years, 14087 members were traced and invited to participate and 11261 (68\%) responded. Preliminary analyses showed there was very little difference in the prevalence of illicit drug use at 16 years among those who did and did not participate in the survey at 30 years $(7.0 \%$ vs $7.2 \%)$.

\section{Assessment of illicit drug use at age 16 years}

Exposures, assessed at 16 years of age, were derived from questions asking, 'Have you ever tried taking cannabis?' (repeated for glue/solvents, amphetamines, barbiturates, cocaine, heroin and lysergic acid diethylamide (LSD)). Street names of drugs were also provided. Responses were combined across drugs and categorised into never, taken but not in the past year and taken in the past year.

\section{Outcome assessment at age $\mathbf{3 0}$ years}

Thirteen outcomes were chosen from the assessment at 30 years. These were chosen to test 
associations across a number of health and economic domains. Health behaviours comprised illicit drug use (ever and in the past year), including the use of cannabis, cocaine, crack, ecstasy, amphetamines, poppers, temazepam, ketamine, magic mushrooms, LSD, heroin, methadone and other drugs. Street names of drugs were provided. All participants, apart from lifelong teetotallers, were asked to complete questions on possible problems with alcohol using the Cutting down, being Annoyed by criticism, feeling Guilty, and Eye-openers (CAGE) questionnaire. ${ }^{16}$ Smoking every day was defined as smoking at least one cigarette every day in the past week. Mental health problems were assessed using enquiries on having seen a specialist medical provider since age 16 because of a problem with illicit drugs; a mental health problem; or a psychological morbidity based on a score of $\geq 7$ on the Rutter Malaise Inventory. ${ }^{17}$ Physical health was ascertained from self-reports of accidents that occurred since 16 years that required treatment by a doctor. These included a subset that were due to a mugging or a violent or sexual assault. Socioeconomic disadvantage was based on employment status and whether participants had been homelessness since 16 years. Finally, study members reported having been arrested, formally cautioned or found guilty in a court since 16 years of age.

\section{Covariates}

Covariates, identified a priori, were chosen based on previous studies showing an association with adolescent and/or adult illicit drug use. At 16 years of age, these included the number of units of alcohol consumed in the past week, smoking in the past week, psychological morbidity (score of $\geq 7$ on the Rutter Malaise inventory), ${ }^{17}$ and occupational social class based on mother's and father's occupation provided by parents at interview and coded using the Registrar General's classification system. ${ }^{18}$

\section{Statistical methods}

We took two approaches to deal with missing data. The primary approach was to impute all missing exposure, outcome and covariate data (multiple imputation, MI) using information from over 40 variables associated with our measures or missingness to make the assumption that data were 'missing at random' more plausible. We conducted a sensitivity analysis using multiple imputation then deletion (MID) whereby exposure, outcome and covariate data are imputed, but outcome is then deleted before analysis. MID has been found to produce more precise estimates than MI and can help minimise bias if the model for imputing outcome data is mis-specified (ie, because imputed outcome data are removed before analysis). ${ }^{19}$ For both MI and MID, we generated 20 imputed datasets.

We compared the characteristics of participants with and without complete data. Logistic regression was used to calculate ORs and 95\% CIs to summarise the association between illicit drug use at 16 years of age and later outcomes. In preliminary analyses, there was no difference in results in men and women, so data were pooled and sex-adjusted. Illegal drug use at 16 years was modelled as a binary variable (never vs use in the past year) or as a categorical variable (never vs taken but not in the past year, used in the past year). The primary analysis was the testing of doseresponse associations by modelling the categorical drug use exposure variable as a linear term. To reduce the risk of generating spurious findings due to multiple testing, we applied the Bonferroni correction to the tests of trend across categories of drug use. ${ }^{20}$ This meant that only p-values for a test of trend of $<0.004(\mathrm{p}=0.05 / 13)$ were considered significant. ORs were adjusted for sex, parental social class and the Rutter Malaise Inventory at 16 years, plus the baseline status of the outcome variable if it was available at 16 years. All analyses were performed using Stata, version 15.1.

\section{RESULTS}

There were 14082 participants who provided data at either 16 or 30 years of age. The MID sample with complete outcome data was 9651 and with complete exposure, outcomes and covariates was 1858. Participants with complete data were more likely at 16 years to be female, have parents with a managerial or professional occupation, seen a doctor for a mental health problem, have a psychological morbidity, have had an accident and less likely to have used an illicit drug (ever, or in the past year), seen a specialist or been to a hospital because of drug problems, been homeless or had any police/criminal justice experiences, than those who did not have complete data. Our primary results are based on analyses with the MI sample as they offered greater precision $(n=14082$ participants; 6999 women).

At 16 years, $20.3 \%$ of the participants had ever tried an illicit drug, with $7.2 \%$ having used in the past year. Of those who used in the past year, $87.0 \%$ only used cannabis. Of the 13 outcomes studied, after adjustment for confounding factors, adolescent illicit drug use was associated with all adult outcomes measured except for having possible problems with alcohol, getting treatment for an accident or being unemployed (figure 1). After correction for multiple testing, there was a significant linear trend across categories of illicit drug use for five outcomes at 30 years of age: illicit drug use in the past year, having been homeless, arrested, formally cautioned and found guilty in a court (table 1). Sensitivity analysis using the MID sample (online supplementary tables 1 and 2) and the sample with no missing data was not materially different to those using the MI sample (online supplementary tables 3 and 4). As there were no participants in the sample with no missing data who had seen a specialist with a problem with drugs, were unemployed or been homeless, we could not generate estimates for these outcomes.

\section{DISCUSSION}

In this population-wide birth cohort study, illicit drug use during adolescence was associated with a wide range of adverse outcomes in early adulthood. These included an association with illicit drug use in the past year, having been homeless and criminal justice experiences. These associations were not explained by parental socioeconomic status or psychological morbidity in adolescence.

\section{Comparison with existing studies}

Our analyses examined illicit drug use but replicate those from smaller cohort studies that have investigated cannabis and amphetamine use in the United States, New Zealand and Australia. These studies have shown that cannabis use in adolescence is associated with negative outcomes across a number of domains, including drug use in early adulthood, ${ }^{1}{ }^{2}$ daily smoking, ${ }^{12}$ alcohol use disorders, ${ }^{3}$ mental health problems ${ }^{3} 421$ (in particular cannabis with psychosis $^{22}$ and psychotic disorders ${ }^{23}$ ) and involvement in criminal activity. ${ }^{12} 24$ They replicate the findings of the Victoria Adolescent Health Cohort Study showing amphetamine use in adolescence was associated with 


Health behaviour
Illicit drug use in the past year
Smoke every day
Alcohol problem (CAGE score 22 )
Mental health
Seen specialist for problem with illicit drugs since 16 years of age
Seen specialist for psychiatric problem since 16 years of age
Psychiatric morbidity (Malaise score $\geq 7$ )
Physical health
Seen doctor since 16 years of age to get treatment for an accident
Seen doctor since 16 years of age to get treatment for a violent assault, mugging or sexual assault
Socioeconomic disadvantage
Unemployed
Homeless since 16 years of age
Police/criminal justice experiences
Arrested by police since 16 years
Formally cautioned by police since 16 years
Been found guilty in court since 16 years

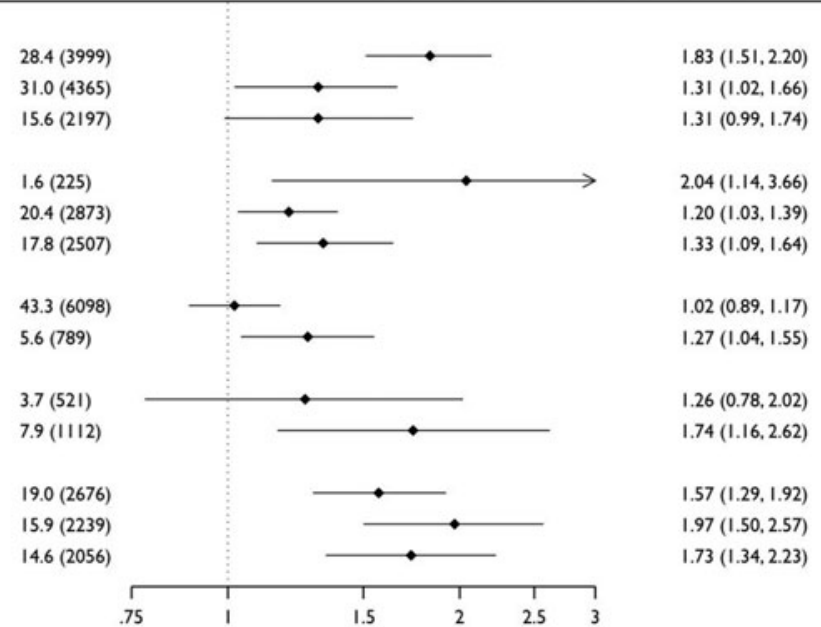

Figure 1 ORs (95\% Cls) for adult outcomes of lifetime illicit drug use in adolescence ( $n=14082)$. Reference category was 'never used illicit drugs'. ORs are adjusted for sex, parental social class and the Rutter Malaise Inventory at 16 years. When available, age 16-year (baseline) assessments of outcomes were added to multivariable models. This included adjusting for screening positive on the Rutter Malaise Inventory at 16 years for the outcome at 30 years of having seen a specialist for a psychiatric problem; units of alcohol consumed in the past week at 16 years for the outcome at 30 years of screening positive for alcohol dependency; and the number of cigarettes smoked per week at 16 years for the outcome at 30 years of smoking every day.

\begin{tabular}{|c|c|c|c|c|}
\hline \multicolumn{5}{|l|}{ Illicit drug use at 16 years } \\
\hline Outcome at 30 years* & Never & $\begin{array}{l}\text { Taken but not in the } \\
\text { past year }\end{array}$ & $\begin{array}{l}\text { Taken in the } \\
\text { past year }\end{array}$ & $\begin{array}{l}\mathrm{p} \text {-Value for } \\
\text { trend }\end{array}$ \\
\hline \multicolumn{5}{|l|}{ Health behaviour } \\
\hline Illicit drug use in the past year & 1 (Reference) & $1.57(1.27,1.94)$ & $2.36(1.80,3.09)$ & $<0.001$ \\
\hline Smoke every day & 1 & $1.20(0.93,1.54)$ & $1.52(1.10,2.12)$ & 0.02 \\
\hline Alcohol problem (CAGE score $\geq 2$ ) & 1 & $1.17(0.86,1.58)$ & $1.59(1.10,2.26)$ & 0.02 \\
\hline \multicolumn{5}{|l|}{ Mental health } \\
\hline Seen specialist for problem with illicit drugs since 16 years of age & 1 & $1.63(0.86,3.10)$ & $2.71(1.22,6.01)$ & 0.01 \\
\hline Seen specialist for psychiatric problem since 16 years of age & 1 & $1.19(1.01,1.40)$ & $1.22(0.94,1.60)$ & 0.03 \\
\hline Psychiatric morbidity (Malaise score $\geq 7$ ) & 1 & $1.35(1.09,1.67)$ & $1.31(1.00,1.72)$ & 0.01 \\
\hline \multicolumn{5}{|l|}{ Physical health } \\
\hline Seen doctor since 16 years of age to get treatment for an accident & 1 & $1.03(0.88,1.20)$ & $1.00(0.83,1.22)$ & 0.88 \\
\hline $\begin{array}{l}\text { Seen doctor since } 16 \text { years of age to get treatment for a violent assault, mugging or } \\
\text { sexual assault }\end{array}$ & 1 & $1.27(0.99,1.63)$ & $1.27(0.90,1.80)$ & 0.03 \\
\hline \multicolumn{5}{|l|}{ Socioeconomic disadvantage } \\
\hline Unemployed & 1 & $1.24(0.74,2.08)$ & $1.27(0.68,2.37)$ & 0.36 \\
\hline Homeless since 16 years of age & 1 & $1.54(1.04,2.29)$ & $2.11(1.32,3.37)$ & 0.002 \\
\hline \multicolumn{5}{|l|}{ Police/criminal justice experiences } \\
\hline Arrested by police since 16 years of age & 1 & $1.55(1.23,1.94)$ & $1.63(1.23,2.17)$ & $<0.001$ \\
\hline Formally cautioned by police since 16 years of age & 1 & $1.74(1.34,2.25)$ & $2.41(1.59,3.63)$ & $<0.001$ \\
\hline Been found guilty in court since 16 years of age & 1 & $1.53(1.15,2.04)$ & $2.12(1.59,2.83)$ & $<0.001$ \\
\hline
\end{tabular}

*Reference category was 'never used illicit drugs'. ORs are adjusted for sex, parental social class and the Rutter Malaise Inventory at 16 years. When available, age 16 -year (baseline) assessments of outcomes were added to multivariable models. This included adjusting for screening positive on the Rutter Malaise Inventory at 16 years for the outcome at 30 years of having seen a specialist for a psychiatric problem; units of alcohol consumed in the past week at 16 years for the outcome at 30 years of screening positive for alcohol dependency; and the number of cigarettes smoked per week at 16 years for the outcome at 30 years of smoking every day.

CAGE, Cutting down, being Annoyed by criticism, feeling Guilty, and Eye-openers questionnaire.

daily smoking, alcohol dependency, drug use in the past year and psychological distress in early adulthood. ${ }^{5}$ Our findings extend these by showing that after adjusting for early life socioeconomic disadvantage and multiple comparisons there was an association between adolescent drug use with being homeless and being convicted in a criminal court.

\section{Potential mechanisms}

The associations between drug use and adult outcomes we observed might be direct, indirect or due to confounding. In support of a direct effect, discordant twin studies have found the cannabis-using twin was more likely to use other illicit drugs at a later date ${ }^{67}$ and report psychotic-like experiences, ${ }^{25}$ than the 
twin who did not. In the Christchurch birth cohort, associations between cannabis use with juvenile offending were attenuated after adjusting for affiliation with substance using or delinquent peers. ${ }^{24}$ In the present submission, criminal justice experiences might be acting as a mediator by increasing time with delinquent or older peers in whom drug use may be more prevalent. This may in turn lead adolescents to taking drugs themselves. An alternative explanation is that these associations are brought about by confounding, whereby both adolescent drug use and later adulthood outcomes share common antecedents such as conduct/oppositional disorders, ${ }^{24}$ delinquency, ${ }^{12}$ and peer $^{26}$ or parental drug use. ${ }^{27}$ This explanation suggests illicit drug use is better characterised as a marker rather than a cause of a life trajectory that is more likely to experience substance misuse, homelessness, the criminal justice system and poor mental health in later life.

\section{Strengths and limitations}

This study has several strengths, including the wide range of outcomes available, extended follow-up into early adulthood and the wealth of potential confounding factors that we adjusted for in our analyses. The main limitation of this study is loss to follow-up and missing data. These may have introduced selection bias into the complete case sample. We therefore used MI to minimise this bias. Sensitivity analysis comparing the results from the complete case to the imputed datasets provided no evidence that missing data introduced bias. The sensitive nature of reporting illicit drug use and police and criminal justice experiences may have resulted in under-reporting. In 2004, the UK's Misuse of Drugs Act 1971 was amended introducing discretionary warnings for cannabis possession. As drug use was reported in the present cohort in 1986, it is possible that cases of cannabis possession now would not result in the criminal justice outcomes we observed.

\section{CONCLUSIONS}

We found illicit drug use in adolescence is associated with significant socioeconomic adversity and poorer health outcomes in adulthood. If causal, these associations would suggest that illicit drug use in adolescence contributes to the development of health and economic inequalities in the transition to adulthood.

\section{What is already known on this subject}

- Illicit drug use in adolescence has previously been shown to be associated with an increased risk of drug use, delinquency, violence and poor mental health during adulthood.

- Few studies have examined associations with adult social, economic and criminal justice outcomes.

\section{What this study adds}

- We found new links between illicit drug use in adolescence and an increased risk of experiencing homelessness, being arrested and/or cautioned by the police, and being found guilty at court. These associations were not explained by parental socioeconomic status or psychological morbidity in adolescence.

- Illicit drug use in adolescence may contribute to the development of health and economic inequalities in the transition to adulthood.
Contributors JW and GDB had the idea and designed the analyses. JW acquired the data and undertook the analyses. SB contributed to refining the analyses and drafted the figure. All authors drafted the manuscript and approved its publication.

Funding JW is funded by The Centre for the Development and Evaluation of Complex Interventions for Public Health Improvement (DECIPHer), a UKCRC Public Health Research Centre of Excellence. Joint funding (MR/KO232331/1) from the British Heart Foundation, Cancer Research UK, Economic and Social Research Council, Medical Research Council, the Welsh Government and the Wellcome Trust, under the auspices of the UK Clinical Research Collaboration, and is gratefully acknowledged. GDB is supported by the UK Medical Research Council (MR/P023444/1) and the US National Institute on Aging (1R56AG052519-01; 1R01AG052519-01A1). SB is supported by the National Institute for Health Research (NIHR) Blood and Transplant Research Unit in Donor Health and Genomics (NIHR BTRU-2014-10024), UK Medical Research Council (MR/L003120/1), British Heart Foundation (SP/09/002; RG/13/13/30194; RG/18/13/3394/6) and the NIHR Cambridge Biomedical Research Centre at the Cambridge University Hospitals NHS Foundation Trust.

Competing interests None declared.

Patient consent for publication Not required.

Ethics approval Plewis I, Calderwood L, Hawkes D, Nathan G. National Child Development Study and 1970 British Cohort Study technical report: Changes in the NCDS and BCS70 populations and samples over time. London: Institute of Education. 2004.

Data sharing statement All data are openly available from the UK Data Archive (https://discover.ukdataservice.ac.uk/).

Provenance and peer review Not commissioned; externally peer reviewed.

\section{ORCID iDs}

James White http://orcid.org/0000-0001-8371-8453

G David Batty http://orcid.org/0000-0003-1822-5753

\section{REFERENCES}

1 Swift W, Coffey C, Degenhardt L, et al. Cannabis and progression to other substance use in young adults: findings from a 13-year prospective population-based study. J Epidemiol Community Health 2012;66:e26.

2 Hall W. What has research over the past two decades revealed about the adverse health effects of recreational cannabis use? Addiction 2015;110:19-35.

3 Blanco C, Hasin DS, Wall MM, et al. Cannabis use and risk of psychiatric disorders: prospective evidence from a US National Longitudinal Study. JAMA Psychiatry 2016;73:388-95.

4 Gobbi G, Atkin T, Zytynski T, et al. Association of cannabis use in adolescence and risk of depression, anxiety, and suicidality in young adulthood: a systematic review and meta-analysis. JAMA Psychiatry [Internet] 2019. Available https://jamanetwork.com/ journals/jamapsychiatry/fullarticle/2723657 (accessed 22 Mar 2019).

5 Degenhardt L, Coffey C, Moran P, et al. The predictors and consequences of adolescent amphetamine use: findings from the Victoria Adolescent Health Cohort Study. Addiction 2007; 102:1076-84.

6 Lynskey MT, Heath AC, Bucholz KK, et al. Escalation of drug use in early-onset cannabis users vs co-twin controls. JAMA 2003;289:427-33.

7 Lynskey MT, Vink JM, Boomsma DI. Early onset cannabis use and progression to other drug use in a sample of Dutch twins. Behav Genet 2006;36:195-200.

8 Marconi A, Di Forti M, Lewis CM, et al. Meta-analysis of the association between the level of cannabis use and risk of psychosis. Schizophr Bull 2016;42:1262-9.

9 Large M, Sharma S, Compton MT, et al. Cannabis use and earlier onset of psychosis: a systematic meta-analysis. Arch Gen Psychiatry 2011;68:555-61.

10 Stiby Al, Hickman M, Munafò MR, et al. Adolescent cannabis and tobacco use and educational outcomes at age 16: birth cohort study. Addict Abingdon Engl 2015;110:658-68

11 Lynskey M, Hall W. The effects of adolescent cannabis use on educational attainment: a review. Addict Abingdon Engl 2000;95:1621-30.

12 Brook JS, Balka EB, Whiteman M. The risks for late adolescence of early adolescent marijuana use. Am J Public Health 1999;89:1549-54

13 Elliott J, Shepherd P. Cohort profile: 1970 British Birth Cohort (BCS70). Int J Epidemiol 2006;35:836-43.

14 von Elm E, Altman DG, Egger M, et al. Strengthening the Reporting of Observational Studies in Epidemiology (STROBE) statement: guidelines for reporting observational studies. BMJ 2007;335:806-8.

15 Goodman A, Butler N. BCS70: the 1970 British Cohort Study: the sixteen-year followup. London, England, United Kingdom: Inst Educ Lond, 1987.

16 Ewing JA. Detecting alcoholism. The CAGE questionnaire. JAMA 1984;252:1905-7.

17 Rodgers B, Pickles A, Power C, et al. Validity of the Malaise Inventory in general population samples. Soc Psychiatry Psychiatr Epidemiol 1999;34:333-41.

18 General R. Classification of occupations. London: HM Stationery Office, 1980.

19 Von Hippel PT. 4. Regression with missing Ys: an improved strategy for analyzing multiply imputed data. Sociol Methodol 2007;37:83-117.

20 VanderWeele TJ, Mathur MB. Some desirable properties of the Bonferroni correction: is the Bonferroni correction really so bad? Am J Epidemiol 2019;188:617-18. 
21 Patton GC, Coffey C, Carlin JB, et al. Cannabis use and mental health in young people: cohort study. BMJ 2002;325:1195-8.

22 McGrath J, Welham J, Scott J, et al. Association between cannabis use and psychosis-related outcomes using sibling pair analysis in a cohort of young adults. Arch Gen Psychiatry 2010;67:440-7.

23 Forti MD, Quattrone D, Freeman TP, et al. The contribution of cannabis use to variation in the incidence of psychotic disorder across Europe (EU-GEI): a multicentre case-control study. Lancet Psychiatry [Internet]. 2019. Available https://www.the lancet.com/journals/lanpsy/article/PIIS2215-0366(19)30048-3/abstract (accessed 22 Mar 2019).
24 Fergusson DM, Lynskey MT, Horwood LJ. The short-term consequences of early onset cannabis use. J Abnorm Child Psychol 1996;24:499-512.

25 Karcher NR, Barch DM, Demers CH, et al. Genetic predisposition vs individual-specific processes in the association between psychotic-like experiences and cannabis use. JAMA Psychiatry 2019;76:87-94.

26 Van Ryzin MJ, Fosco GM, Dishion TJ. Family and peer predictors of substance use from early adolescence to early adulthood: an 11-year prospective analysis. Addict Behav 2012;37:1314-24.

27 Bahr SJ, Hoffmann JP, Yang X. Parental and peer influences on the risk of adolescent drug use. J Prim Prev 2005;26:529-51. 